\title{
Bone loss and biomechanical reduction of appendicular and axial bones under ketogenic diet in rats
}

\author{
JIANYANG DING* ${ }^{*}$ XIAOLIN XU*, XIUHUA WU, ZUCHENG HUANG, GANGGANG KONG, \\ JUNHAO LIU, ZHIPING HUANG, QI LIU, RONG LI, ZHOU YANG, YAPU LIU and QINGAN ZHU
}

\begin{abstract}
Department of Spine Surgery, Nanfang Hospital, Southern Medical University, Guangzhou, Guangdong 510515, P.R. China
\end{abstract}
Received August 15,2018; Accepted December 13, 2018

DOI: $10.3892 / \mathrm{etm} .2019 .7241$

\begin{abstract}
A ketogenic diet (KD) is composed of low-carbohydrate, high-fat and adequate levels of protein. It has been used for decades as a method to treat pediatric refractory epilepsy. However, recently, its side effects on the bones have received increasing attention. In order to comprehensively evaluate the effect of KD on the microstructures and mechanical properties of the skeleton, 14 male Sprague-Dawley rats were equally divided into two groups and fed with a KD (ratio of fat to carbohydrate and protein, 3:1) or a standard diet for 12 weeks. Body weight, as well as blood ketone and glucose levels, were monitored during the experiment. Bone morphometric analyses via micro-computerized tomography were performed on cortical and trabecular bone at the middle L4 vertebral body, the proximal humerus and tibia. The compressive stiffness and strength of scanned skeletal areas were calculated using micro-finite element analysis. The KD led to higher ketone levels and lower glucose levels, with reduced body weight and total bone mineral density (TBMD). After 12 weeks, the diet reduced the bone volume fraction, the trabecular number of cancellous bone, cortical thickness, total cross-sectional area inside the periosteal envelope and the bone area of cortical bone in the tibia and humerus, while increasing trabecular separation. However, KD may not affect the L4 vertebral body. The serum calcium or phosphate concentrations in the blood remained unchanged. In addition, bone stiffness and strength were clearly decreased by the $\mathrm{KD}$, and significantly correlated with the BMD and bone area at all scanned sites. In conclusion, KD led to significant bone loss and reduced biomechanical function in appendicular bones, with a lesser impact on axial bones.
\end{abstract}

Correspondence to: Dr Qingan Zhu, Department of Spine Surgery, Nanfang Hospital, Southern Medical University, 1838 North Guangzhou Avenue, Guangzhou, Guangdong 510515, P.R. China E-mail: qinganzhu@gmail.com

\section{${ }^{*}$ Contributed equally}

Key words: ketogenic diet, microstructure, finite element, mechanical properties, appendicular bones, axial bones

\section{Introduction}

A ketogenic diet (KD) consists of low carbohydrate, high fat and adequate protein. This diet was designed to simulate the biochemical effects of fasting, which is used for the treatment of drug-refractory seizures $(1,2)$. By limiting the intake of carbohydrates, it forces the body to switch to fatty acid oxidation as an energy source, leading to a ketogenic state. This KD guarantees sufficient calories for normal activity produced through ketogenesis, which occurs principally in the mitochondrial matrix of the liver $(3,4)$. While KD is a classic therapy for refractory epilepsy, recent animal studies have demonstrated that it is also effective in the treatment of other neurodegenerative diseases, including Parkinson's disease, amyotrophic lateral sclerosis, Alzheimer's disease and traumatic brain injury (5-10).

Although KD has been used as a dietary regimen for managing pediatric refractory epilepsy over the past decades, its side effects remain controversial. Clinical trials have suggested that $\mathrm{KD}$ is safe and efficient $(11,12)$; however, it also resulted in a progressive loss of bone mineral content in pediatric patients, particularly in those with a low body mass index (BMI) (13). A previous study by our group confirmed that KD resulted in a significant bone loss in the tibia and reduced mechanical function in the femur of mice (14); such side effects in cancellous-rich bones, e.g. the vertebrae, are worthy of further investigation. In addition, the association between bone loss and mechanical reduction under KD requires clarification.

Clinically, osteoporosis is associated with a reduced bone mineral density (BMD) and micro-architectural changes, resulting in diminished bone strength and an increased risk of fractures $(15,16)$. Osteoporosis-associated fractures may lead to substantial long-term disability and decreased quality of life (17). Thus, it is necessary to identify the osteoporosis-inducing effects of KD in various parts of the skeleton, including reduced mechanical function of vertebral bones. Micro-finite element (FE), based on the 3-dimensional (3D) bone microarchitecture with high-resolution peripheral quantitative computed tomography (CT), is used to examine age-associated changes (18), effects of disease (19) and outcomes of various treatments on the bone microstructure (20). Analysis of bone mechanical performance using a micro-CT-based FE model, and correlation with microstructural changes and reduced mechanics of bones under a KD is essential. 
The present study aimed to investigate the effects of a long-term KD on the microarchitecture of appendicular and axial bones, and the compressive stiffness and failure load based on micro-FE analysis in a rat model. The secondary objective was to assess the possible correlation between the microstructural changes and the mechanical properties of appendicular and axial bones.

\section{Materials and methods}

Animal model. A total of 14 male 6-week-old Sprague-Dawley rats (180-200 g; Laboratory Animal Center of Southern Medical University Guangzhou, China) were purchased prior to the 2 weeks of adaptive feeding with a standard diet, then all rats were randomly divided into a control and a KD group $(n=7$ per group). All rats were housed individually in hanging wire cages in an animal facility with the room temperature maintained at $22 \pm 1^{\circ} \mathrm{C}$, humidity maintained at $60-70 \%$ and under a $12-\mathrm{h}$ light/dark cycle. Rats in the control group were fed a standard diet (provided by the Laboratory Animal Center of Southern Medical University), while rats in the KD group received a KD (Jielikang, Shenzhen, China) containing a 3.1:1 ratio of fat to carbohydrate and protein, and the remaining nutrients met the AIN-93 criterion (18). The specific composition of the two diets is provided in Table I. All rats had ad libitum access to tap water and their designated diet throughout the 12 weeks of the study.

Measurement of body weight, and blood ketone and glucose levels. Rats were weighed every 2 weeks. Blood samples $(0.1 \mathrm{ml}$ each time) were obtained from the caudal vein biweekly, and were used to determine blood glucose and blood ketone levels. The Yicheng Blood Ketone Meter T-1 (Sentest, Inc., Beijing, China) and a Medisense Precision Xtra monitor (Abbott Pharmaceutical Co., Ltd., Lake Bluff, IL, USA) were used to measure blood $\beta$-hydroxybutyrate ketone concentrations, and the JPS-5 monitor (Leapon, Inc., Beijing, China) was used to determine blood glucose levels.

Measurement of total (T)BMD by dual energy X-ray absorptiometry (DEXA). Prior to the imaging examination and decapitation, all rats were fasted for $6 \mathrm{~h}$ (to standardize gastrointestinal filling). Following anesthesia with $0.3 \%$ pentobarbital (30 mg/kg), rats were fixed face-down on the testing bed. The TBMD was analyzed with DEXA (GE-Lunar iDXA; GE Healthcare, Little Chalfont, UK).

Specimen preparation. Following anesthesia by intraperitoneal injection of $0.3 \%$ pentobarbital $(30 \mathrm{mg} / \mathrm{kg})$, blood samples were obtained from the inferior vena cava and stored at $4^{\circ} \mathrm{C}$ overnight. The next morning, blood samples were centrifuged at $2,000 \mathrm{x} \mathrm{g}$ for $12 \mathrm{~min}$ at $4^{\circ} \mathrm{C}$, and serum from the supernatant was collected and stored at $-80^{\circ} \mathrm{C}$.

Humerus, tibia and L4 lumbar vertebra samples were fixed in $4 \%$ paraformaldehyde for $24 \mathrm{~h}$ after removal of soft tissues and then stored in $75 \%$ ethanol for subsequent measurements. In addition, the full length of the tibiae, femurs and humeri were measured with a vernier caliper.

Serum analysis. All serum samples were processed as previously described. Circulating concentrations of calcium and phosphate levels (Beckman Coulter, Inc., Brea, CA, USA), and total 25-hydroxy vitamin D (25- (OH)-VD) and 25-dihydroxy vitamin D3 [1,25- $(\mathrm{OH})_{2}-\mathrm{D}_{3}$; activated metabolite of 25- (OH)-VD] contents were measured using commercially available kits [25-(OH)-VD: Cat. no. 10699533; Siemens AG, Munich, Germany; 1,25-(OH) $)_{2}-\mathrm{D}_{3}$ : cat. no. ml028285; Mlbio, Shanghai, China] according to the manufacturer's instructions.

Micro-CT scan. The bone samples were scanned using a high-resolution micro-CT system ( $\mu$ CT 80; Scanco Medical AG, Brüttisellen, Switzerland) with an isotropic voxel size of $12 \mu \mathrm{m}$ (55 kv; $145 \mu \mathrm{A}$; integration time, $300 \mathrm{msec}$; average number of readings, 2). The TBMD, bone volume fraction (BV/TV), trabecular thickness (Tb.Th), trabecular number (Tb.N) and trabecular separation ( $\mathrm{Tb} . \mathrm{Sp}$ ) were measured for the cancellous bone, whereas the total cross-sectional area inside the periosteal envelope (Tarea), bone area (Barea) and cortical thickness (Ct. Th) were measured for the cortical bone. The scanned and analyzed area of humeri and tibiae was a $2.0-\mathrm{mm}$ rectangular region below the epiphyseal line, and the scanned area of the L4 vertebral body was in the middle third region.

FE analysis. FE software is an addition to the Image Processing Language software (version 1.13; Scanco Medical AG, Brüttisellen, Switzerland) for image modification and enhancement. The software uses a set of functions that enable FE analysis of structures as represented by $3 \mathrm{D}$ micro-CT images.

The simulations were performed within the framework of linear elasticity. The elastic material properties were homogeneous (no distinction between cortical and trabecular bone) and isotropic, with a Poisson's ratio of $v=0.3$ and Young's modulus of material=10,000 $\mathrm{MPa}$. A 'high-friction compression test in the z-direction' was selected for the simulation of the compression. The simulation produced the compressive stiffness and failure load of bones.

Statistical analysis. Measurement data are expressed as the mean \pm standard deviation. Two-way repeated-measures analysis of variance was used to analyze the body weight, blood ketone levels and glucose levels, while an independent-samples t-test was selected to compare other parameters between the two dietary groups. The Bivariate Correlations model was used to determine the Pearson correlation coefficients of microstructure and biomechanical parameters. Linear regression was used to analyze the correlation coefficients and significance of two combined microstructure and biomechanical parameters. $\mathrm{P}<0.05$ was considered to indicate a statistically significant difference.

\section{Results}

Body weight, blood ketone and glucose levels. All rats gained weight consistently throughout the experimental period, with the initial body weight ranging from 280-300 g (control, $290.4 \pm 10.6 \mathrm{~g} ; \mathrm{KD}, 291.4 \pm 9.4 \mathrm{~g} ; \mathrm{P}=0.845$ ). The KD group exhibited a significantly slower body weight increase compared with that in the control group throughout the experiment, and a significant difference in body weight growth was observed

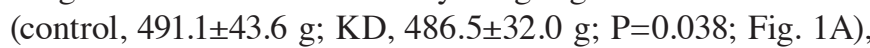
while the differences were significant only at week 3,4 and 5 . 
Table I. Comparison of basic nutrient content between the standard and the ketogenic diet (per $100 \mathrm{~g}$ ).

\begin{tabular}{lcc}
\hline Component/item & Standard diet & Ketogenic diet $^{\mathrm{a}}$ \\
\hline Energy $(\mathrm{kJ})$ & 1,338 & 2,804 \\
Protein $(\mathrm{g})$ & 14.5 & 18.2 \\
Fat $(\mathrm{g})$ & 4 & 65.1 \\
Carbohydrates $(\mathrm{g})$ & 55.5 & 2.7 \\
Dietary fibers $(\mathrm{g})$ & 4.5 & 7.4 \\
Calcium $(\mathrm{mg})$ & 720 & 500 \\
Phosphorus $(\mathrm{mg})$ & 600 & 300 \\
Vitamin D $(\mu \mathrm{g})$ & 2.5 & 2.5
\end{tabular}

${ }^{\text {a}}$ Ratio of fat to carbohydrate and protein: $65 \cdot 1 /(2.7+18.2)=3 \cdot 1: 1$.

The average ketone levels in the two groups were 0.4 and $1.6 \mathrm{mmol} / \mathrm{l}$ in the control and KD group, respectively. The KD group reached a peak ketone level within the first 3 weeks, and the ketone levels were significantly higher level than those in the control group at each time points since week $1(\mathrm{P}<0.01)$. However, the blood glucose levels were $7.0 \mathrm{mmol} / \mathrm{l}$ on average in the control group, which were significantly higher than those in the KD group $(6.0 \mathrm{mmol} / \mathrm{l}$ on average; $\mathrm{P}<0.01$; Fig. 1$)$, and the different were also significant at each time points since week 3 $(\mathrm{P}<0.05)$. The TBMD was $0.153 \pm 0.007 \mathrm{~g} / \mathrm{cm}^{2}$ in the KD group, which was significantly lower than that in the control group $\left(0.162 \pm 0.008 \mathrm{~g} / \mathrm{cm}^{2} ; \mathrm{P}=0.034\right)$.

Bone length. The length of the tibiae was $45.27 \pm 1.60$ and $45.00 \pm 1.35 \mathrm{~mm}$ in the control and KD group, respectively (data not shown). The length of femurs was $41.31 \pm 2.01$ and $41.00 \pm 0.68 \mathrm{~mm}$, and the length of humeri was $31.36 \pm 1.15$ and $31.09 \pm 1.19 \mathrm{~mm}$ in the control and KD group, respectively (data not shown). There was no significant difference in the bone length between the two groups (data not shown).

Concentration of calcium, phosphorus and vitamin D in serum. The calcium concentration was $2.52 \pm 0.06$ and $2.51 \pm 0.09 \mathrm{mmol} / \mathrm{l}$ in the control and KD group, respectively, and the phosphorus concentration was $2.30 \pm 0.21 \mathrm{mmol} / 1$ in the control group and $2.33 \pm 0.24 \mathrm{mmol} / \mathrm{l}$ in the KD group (data not shown). There was no significant difference in the calcium and phosphorus concentration between the two groups (data not shown). Regarding the effect of the KD on vitamin $\mathrm{D}$, the level of total 25-OH-VD (control, 36.0 $\pm 3.5 \mathrm{ng} / \mathrm{ml}$; and $\mathrm{KD}, 35.0 \pm 2.6 \mathrm{ng} / \mathrm{ml}$ ) and active vitamin $\mathrm{D}, 1,25-(\mathrm{OH})_{2}-\mathrm{D}_{3}$ (control, $33.2 \pm 3.8 \mathrm{ng} / \mathrm{ml}$; and $\mathrm{KD}$, $35.7 \pm 3.6 \mathrm{ng} / \mathrm{ml}$ ) exhibited no significant difference between the two groups (data not shown).

Effects of KD on cancellous bones. The KD group exhibited a decreased TBMD, BV/TV and Tb.N, and an increased Tb.Sp compared with that in the control group. In addition, trabecular thickness in the cancellous bone did not change between the groups, indicating that the trabecular structure became sparse following KD intervention (Table II; Figs. 2 and 3). These microstructural parameters were significantly changed in the tibiae and humeri of rats receiving the $\mathrm{KD}$, whereas there were no significant differences in the L4 vertebral body samples between the groups (Table II; Figs. 2 and 3).

Cortical bones. The Tarea and Barea were significantly decreased in the KD group ( 20 and $\sim 25 \%$ in the tibia and humerus, respectively) compared with those in the control group, whereas only a $10 \%$ decrease was obtained in the L4 vertebral body in the KD group, and there was no significant difference compared with the control group (Table II; Figs. 3 and 4). The only significant decrease in the Ct.Th was in the tibiae of rats from the KD group; while the largest decrease in Ct.Th was in the L4 vertebral body of KD group vs. control group rats (23\%), this decrease was not significant (Table II; Figs. 2 and 3).

Micro-FE analysis. The compressive strength and stiffness of the tibiae in the KD group were $0.323 \pm 0.040 \mathrm{kN}$ and $23.1 \pm 3.0 \mathrm{kN} / \mathrm{mm}$, respectively, which were significantly lower than those in the control group $(0.458 \pm 0.044 \mathrm{kN}$ and $35.0 \pm 4.2 \mathrm{kN} / \mathrm{mm}$, respectively). The compressive strength and stiffness of humeri were significantly decreased from $0.293 \pm 0.035 \mathrm{~N}$ and $20.6 \pm 2.9 \mathrm{kN} / \mathrm{mm}$ in the control group to $0.247 \pm 0.010 \mathrm{kN}$ and $17.0 \pm 0.8 \mathrm{kN} / \mathrm{mm}$ in the $\mathrm{KD}$ group, respectively. Although the compressive strength and stiffness of the L4 vertebral body decreased to $0.178 \pm 0.030 \mathrm{kN}(77 \%)$ and $9.4 \pm 1.8 \mathrm{kN} / \mathrm{mm}(75 \%)$ in the KD group, respectively, they were not significantly different from those in the control group (Fig. 4).

Correlation between microstructure and biomechanical parameters. Among the measured microstructural parameters, the $\mathrm{BMD}$ in the cancellous bone and the Barea in the cortical bone were correlated with the compressive stiffness and strength in all three bone types analyzed (Fig. 5). The combination of BMD and Barea achieved a greater correlation with the compressive stiffness (tibia, $\mathrm{R}^{2}=0.858$; humerus, $\mathrm{R}^{2}=0.893$; and $\mathrm{L} 4$ vertebrae, $\mathrm{R}^{2}=0.913$ ) and the compressive failure load (tibia, $\mathrm{R}^{2}=0.813$; humerus, $\mathrm{R}^{2}=0.910$; and $\mathrm{L} 4$ vertebrae, $\mathrm{R}^{2}=0.875$ ) compared with the BMD and Barea correlations alone (Table III).

\section{Discussion}

The present study demonstrated a significant decrease in the TBMD of rats fed KD for 12 weeks, with no difference in the serum calcium and phosphate concentration between the KD and control groups. Specifically, by scanning appendicular bones of the extremities (humerus and tibia) and L4 vertebra using micro-CT, it was observed that KD led to bone loss in cancellous and cortical bones, with insignificant changes in L4 vertebral bone. Furthermore, simulated compressive analysis using micro-FE analysis revealed that the compressive stiffness and strength of appendicular and axial bones were decreased under the KD, and were highly correlated with the microstructural parameters of cancellous and cortical bones.

The effects of KD bone loss in humans remain inconclusive. A previous study has indicated that maintaining a long-term KD did not cause any major negative effects on the bone mineral content and BMD in adults with glucose transporter-1 deficiency syndrome (21). The present study, which only included an animal experiment with a small sample, does not allow for any conclusions regarding the safety of KDs, and the results may 

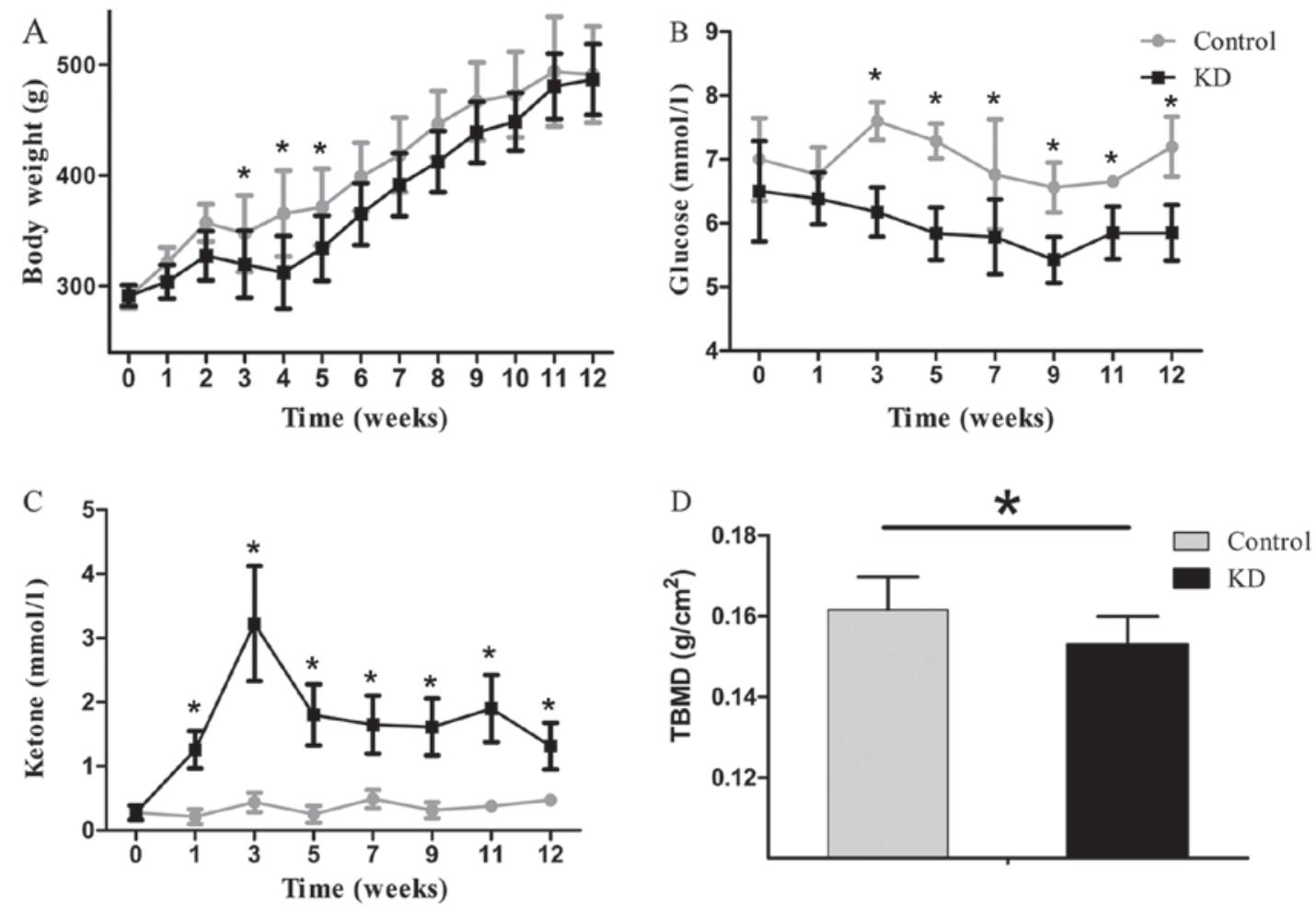

Figure 1. Characteristics of the two groups. (A) Body weight, (B) blood glucose, (C) blood ketone levels and (D) TBMD measured by dual-energy X-ray absorptiometry. " $\mathrm{P}<0.05$. KD, ketogenic diet; TBMD, total bone mineral density.

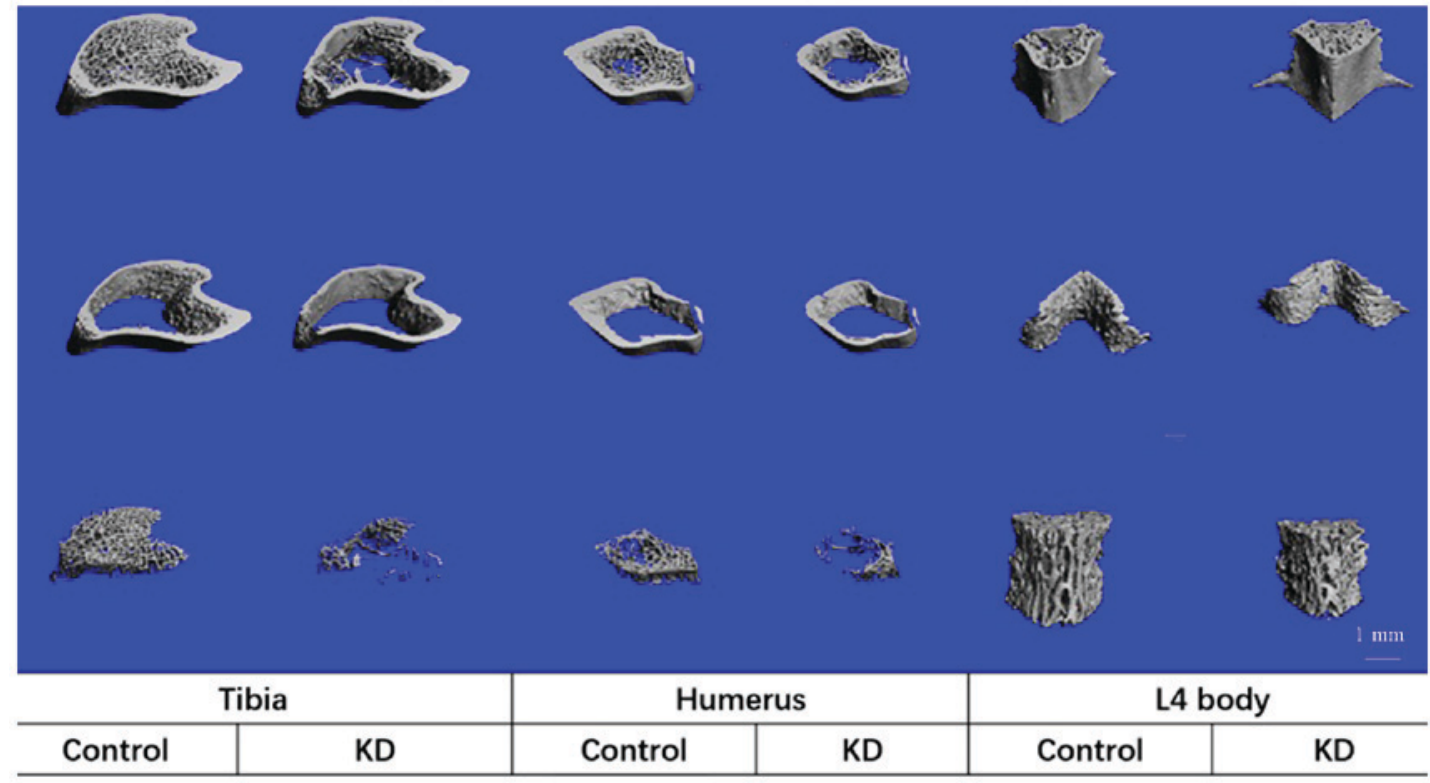

Figure 2. Three-dimensional skeletal images. Micro-computed tomography 3-dimensional images of the region of interest from three skeletal sites. KD, ketogenic diet.

not be comparable with previous studies focusing on children with intractable epilepsy treated with KD $(13,22)$. However, the present study on a ketogenic rat model may enhance the understanding of bone loss due to KD, suggesting that this topic is worthy of further investigation.

Ketogenic animal models are typically established by feeding KD or by $\beta$-hydroxybutyrate administration $(23,24)$; however, to the best of our knowledge, there is currently no unified ketogenic animal model. A previous study by Wu et al (14) has indicated that KD caused bone loss in mouse tibia, but the blood ketone levels in the KD group were only $\sim 1.0 \mathrm{mmol} / \mathrm{l}$. In the present study, elevated blood ketone levels $(\sim 2.0 \mathrm{mmol} / \mathrm{l})$ were achieved with a customized KD $(24,25)$, which indicated that the ketogenic model was efficient. In addition, the present study investigated the bone loss in L4 vertebra and humerus, providing a comprehensive overview of the bone loss in rats under the KD. 
Table II. Micro-computed tomography analysis of cortical and cancellous bone of the proximal tibia, proximal humerus and middle of the L4 vertebrae at 12 weeks.

A, Cancellous bone

\begin{tabular}{|c|c|c|c|c|c|c|}
\hline \multirow[b]{2}{*}{ Parameter } & \multicolumn{2}{|c|}{ Tibia } & \multicolumn{2}{|c|}{ Humerus } & \multicolumn{2}{|c|}{ Vertebrae } \\
\hline & $\mathrm{KD}(\mathrm{n}=6)$ & Control $(n=6)$ & $\mathrm{KD}(\mathrm{n}=6)$ & Control $(n=6)$ & $\mathrm{KD}(\mathrm{n}=4)$ & Control $(n=4)$ \\
\hline $\mathrm{BMD}(\mathrm{mg} / \mathrm{cm})$ & $27.4 \pm 4.4$ & $144.0 \pm 68.0^{\mathrm{a}}$ & $89.4 \pm 16.6$ & $162.0 \pm 37.1^{\mathrm{a}}$ & $201.0 \pm 86.8$ & $285.0 \pm 42.3$ \\
\hline $\mathrm{BV} / \mathrm{TV}$ & $0.049 \pm 0.006$ & $0.191 \pm 0.081^{\mathrm{a}}$ & $0.135 \pm 0.027$ & $0.206 \pm 0.047^{\mathrm{a}}$ & $0.258 \pm 0.110$ & $0.359 \pm 0.050$ \\
\hline Tb.N (mm) & $1.04 \pm 0.14$ & $2.65 \pm 0.85^{\mathrm{a}}$ & $1.16 \pm 0.15$ & $2.34 \pm 0.75^{\mathrm{a}}$ & $2.57 \pm 0.76$ & $3.33 \pm 0.21$ \\
\hline $\mathrm{Tb} . \mathrm{Sp}(\mathrm{mm})$ & $0.99 \pm 0.15$ & $0.40 \pm 0.16^{\mathrm{a}}$ & $0.92 \pm 0.13$ & $0.48 \pm 0.17^{\mathrm{a}}$ & $0.40 \pm 0.15$ & $0.26 \pm 0.02$ \\
\hline Tb.Th (mm) & $0.08 \pm 0.01$ & $0.09 \pm 0.01$ & $0.08 \pm 0.01$ & $0.08 \pm 0.01$ & $0.10 \pm 0.01$ & $0.11 \pm 0.01$ \\
\hline
\end{tabular}

B, Cortical bone

\begin{tabular}{|c|c|c|c|c|c|c|}
\hline \multirow[b]{2}{*}{ Parameter } & \multicolumn{2}{|c|}{ Tibia } & \multicolumn{2}{|c|}{ Humerus } & \multicolumn{2}{|c|}{ Vertebrae } \\
\hline & $\mathrm{KD}(\mathrm{n}=6)$ & Control $(n=6)$ & $\mathrm{KD}(\mathrm{n}=6)$ & Control & $\mathrm{KD}(\mathrm{n}=6)$ & Control $(n=6)$ \\
\hline Tarea $\left(\mathrm{mm}^{2}\right)$ & $6.01 \pm 0.89$ & $7.96 \pm 0.44^{\mathrm{a}}$ & $3.96 \pm 0.25$ & $5.04 \pm 0.40^{\mathrm{a}}$ & $2.61 \pm 0.21$ & $2.86 \pm 0.29$ \\
\hline Barea $\left(\mathrm{mm}^{2}\right)$ & $5.60 \pm 0.863$ & $7.49 \pm 0.39^{\mathrm{a}}$ & $3.47 \pm 0.196$ & $4.37 \pm 0.155^{\mathrm{a}}$ & $2.31 \pm 0.18$ & $2.58 \pm 0.26$ \\
\hline Ct.Th (mm) & $0.281 \pm 0.045$ & $0.355 \pm 0.027^{\mathrm{a}}$ & $0.228 \pm 0.013$ & $0.258 \pm 0.032$ & $0.198 \pm 0.01$ & $0.259 \pm 0.02$ \\
\hline
\end{tabular}

${ }^{\mathrm{a}} \mathrm{P}<0.05 . \mathrm{KD}$, ketogenic diet; BMD, bone mineral density; BV/TV, bone volume fraction; Tb.Th, trabecular thickness; Tb.N, trabecular number; Tb.Sp, trabecular separation; Tarea, total cross-sectional area inside the periosteal envelope; Barea, bone area; Ct.Th, cortical thickness.

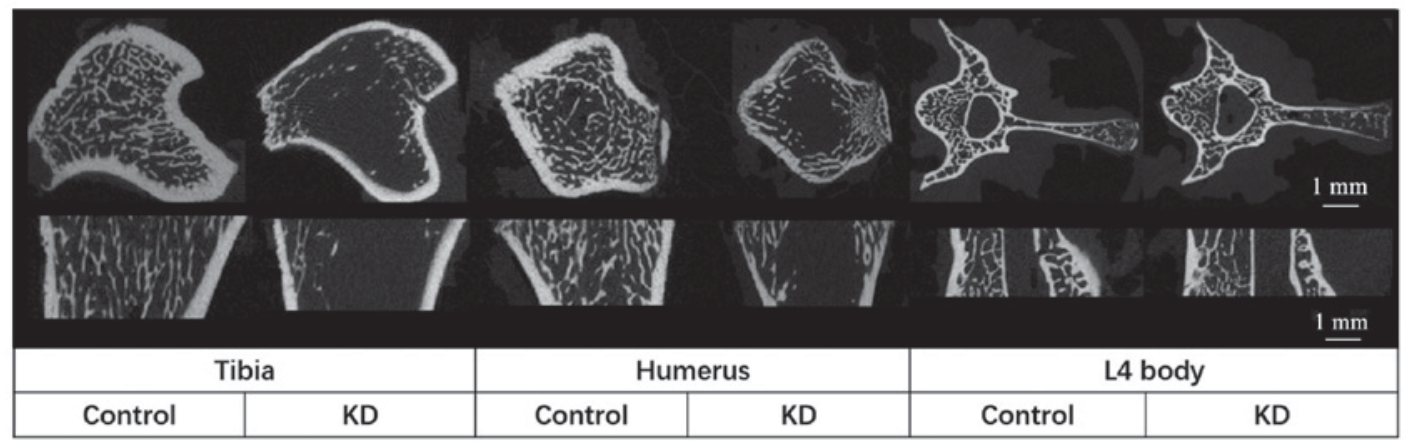

Figure 3. Sectional view contrast of skeletal. Cross-sectional (upper panel) and sagittal (lower panel) plane micro-computed tomography images displaying changes in cancellous and cortical bone of the region of interest from three skeletal sites. KD, ketogenic diet.

Body weight changes may be the first factor associated with bone loss under KD. In the clinic, KD is effective in suppressing the appetite, reducing lipogenesis and increasing lipolysis $(26,27)$, and also results in weight loss (28). A low body weight or BMI is a well-documented risk factor for fracture, and a body weight increase is considered a protective factor against osteoporosis, as mechanical loading and the associated hypertrophy of muscles increases the bone mass (29). Thus, theoretically, rats with low body weight have a lower bone mass, which is in accordance with the results of the present study.

Furthermore, previous studies have reported that chronic ketoacidosis led to an increase in bone minerals to maintain the buffering capacity and decrease renal conversion of 25-(OH)-VD to $1,25-(\mathrm{OH})_{2}-\mathrm{VD}_{3}(30)$. Low $25-(\mathrm{OH})-\mathrm{VD}$ levels, particularly those $<20 \mathrm{ng} / \mathrm{ml}$, were associated with an elevated fracture risk in women aged $\geq 50$ years during a 15 -year follow-up period (31). However, in the present study, the levels of serum calcium and phosphorus in the KD group were similar to those in the standard diet group; this trend was also observed in the total vitamin D and active vitamin D levels, which implied that neither the bone mineral content nor the conversion of vitamin $\mathrm{D}$ is a key factor for the bone loss under the KD.

The present study used DEXA to evaluate the TBMD as a primary endpoint in rats fed with the KD. DEXA is the gold standard for the diagnosis of osteoporosis, and the T-score is highly correlated with the fracture risk (32). While the present results indicated an obvious decrease in the TBMD in the KD group, the bone loss within certain specific bones required further evaluation. In order to determine microstructural changes of different bones in detail, micro-CT analysis was 
Table III. Correlation coefficients between microstructure parameters and biomechanics parameters.

\begin{tabular}{llll}
\hline Parameter & BMD & Barea & Combination \\
\hline Stiffness & & & \\
Tibia & $0.699^{\mathrm{a}}$ & $0.736^{\mathrm{a}}$ & $0.858^{\mathrm{a}}$ \\
Humerus & $0.898^{\mathrm{a}}$ & $0.395^{\mathrm{b}}$ & $0.893^{\mathrm{a}}$ \\
Vertebrae & $0.676^{\mathrm{a}}$ & $0.817^{\mathrm{a}}$ & $0.913^{\mathrm{a}}$ \\
Failure load & & & \\
Tibia & $0.636^{\mathrm{a}}$ & $0.725^{\mathrm{a}}$ & $0.813^{\mathrm{a}}$ \\
Humerus & $0.898^{\mathrm{a}}$ & $0.473^{\mathrm{a}}$ & $0.910^{\mathrm{a}}$ \\
Vertebrae & $0.633^{\mathrm{a}}$ & $0.802^{\mathrm{a}}$ & $0.875^{\mathrm{a}}$ \\
\hline
\end{tabular}

${ }^{\mathrm{a}} \mathrm{P}<0.01,{ }^{\mathrm{b}} \mathrm{P}<0.05$. BMD, bone mineral density in the trabecular bone; Barea, bone area in the cortical bone.
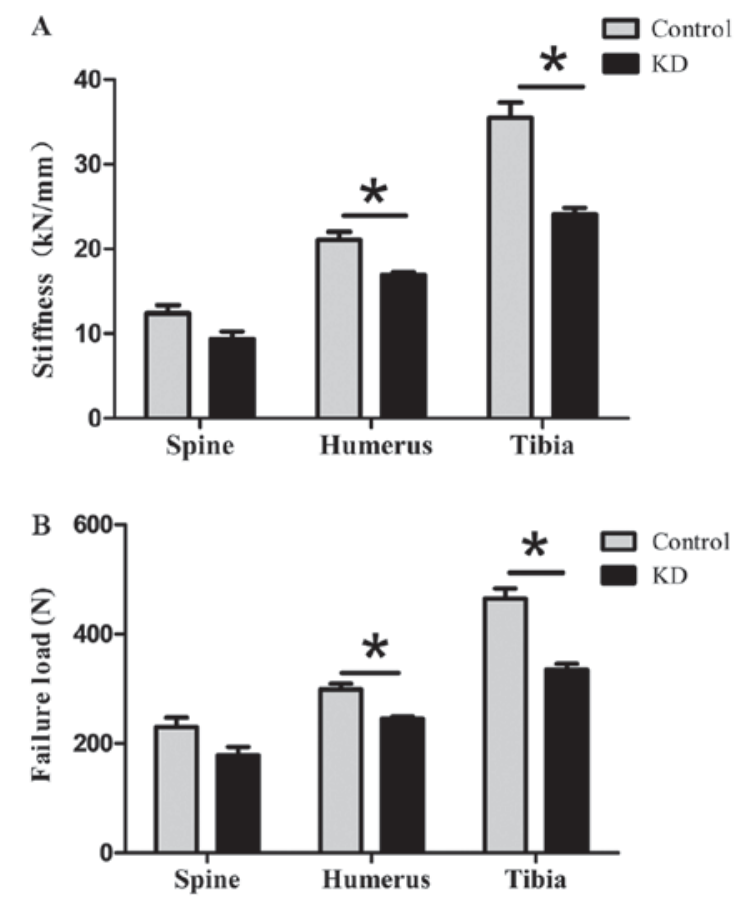

Figure 4. Comparison of biomechanical parameter. (A) Stiffness and (B) failure load in the compression test simulated by finite element at three skeletal sites. ${ }^{*} \mathrm{P}<0.05$. KD, ketogenic diet.

performed on the bones of the upper limbs, lower limbs and axial skeleton.

KD led to cancellous and cortical bone loss in the tibia and humerus, which was consistent with findings of tibia bone loss in a previous study by our group (14). A previous study by our group demonstrated that KD specifically caused cortical bone loss of tibiae in mice when compared with ovariectomized mice (14). The present study also investigated the bone loss in middle of L4 vertebra and the humerus, providing a comprehensive overview of the bone loss under KD. Furthermore, the present study revealed that the most severe trabecular bone loss and structural deterioration occurred in the metaphyseal area of the tibia, and was sensitive to the location selected. By contrast, similar cortical bone loss occurred in the tibia and humerus, while a lesser decrease was apparent in appendicular bones. In spite of greater microstructural changes in cancellous bone of L4 vertebral bodies in the KD group, the present study failed to detect significant changes, potentially due to the small sample size. However, the thickness of trabecular bone remained unchanged between the KD rats and the control group, which indicated a decrease in trabecular bone density associated with the bone loss.

The present study further verified the biomechanical changes under the KD, and a correlation between the bone morphological changes with the bone function was identified. Previous studies have estimated bone strength using high-resolution peripheral quantitative $\mathrm{CT}$ and the FE method, and provided important insight into fracture risk in patients $(33,34)$. The present study used a micro-FE model based on the micro-CT images, and evaluated the compressive stiffness and strength of appendicular and axial bones under the KD. The micro-FE analysis is suitable in cases where the sample size is small and the region of interest unavailable for actual mechanical tests. A significant decrease in biomechanical performance of appendicular bones was detected by micro-FE analysis. The non-significant decrease in compressive stiffness and strength of L4 vertebrae in KD group was potentially due to the small sample size $(n=4)$. These biomechanical features were consistent with the microstructural changes of the appendicular and axial bones under $\mathrm{KD}$. The results of the present study suggest that KD therapy for $\sim 12$ weeks increases the risk of fracture.

Mechanical properties may be correlated with microstructural parameters; however, the correlation coefficient between the compressive stiffness and a single microstructural parameter was dissatisfactory in the present study. BMD, as the gold standard for evaluating bone strength, is associated with bulk modulus through a power law association in bone ( $\mathrm{cm} \mathrm{scale)}$. By contrast, the association is weak at the tissue level $(\mu \mathrm{m}-\mathrm{mm}$ scale), likely due to the effect of microstructural features at small-length scales (35). In vitro studies have demonstrated that the combination of the trabecular microarchitecture and BMD improved the prediction of trabecular bone mechanical behavior and vertebral strength $(36,37)$. In the present study, the combination of the BMD of trabecular bone with the Barea of cortical bone produced a satisfactory prediction of bone mechanical properties, with the adjusted $\mathrm{R}^{2}$ ranging from 0.81 to 0.91 .

The effects of diet on bone microstructure may be achieved by reduced mineral absorption or increased bone turnover. The present study confirmed that KD did not affect mineral absorption, suggesting that the KD affected the bone metabolism. In the present study, the KD successfully converted glycometabolism to ketone body metabolism, as ketone levels were high and blood glucose levels were low (38). Although no increase in bone turnover induced by a low-carbohydrate diet was observed in humans (39), our previous studies have confirmed that $\mathrm{KD}$ and ovariectomy resulted in a similar promotion of bone absorption via activation of osteoclasts, rather than inhibition of bone formation mediated by osteoblasts (14). In addition, certain studies have reported that ketone bodies are important endogenous factors that may regulate bone metabolism under physiological and pathological conditions, as the ketone bodies modulate osteoblast functions bi-directionally (40).

The effects of KD on bone loss have been rarely reported $(14,22)$. The present study demonstrated more general 
Tibia

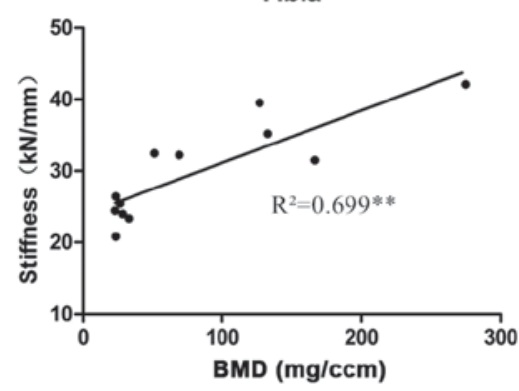

Tibia

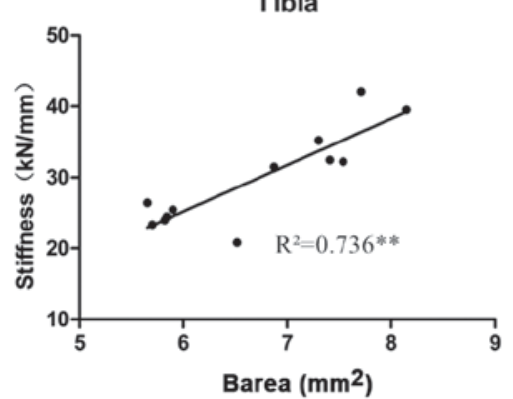

Humerus

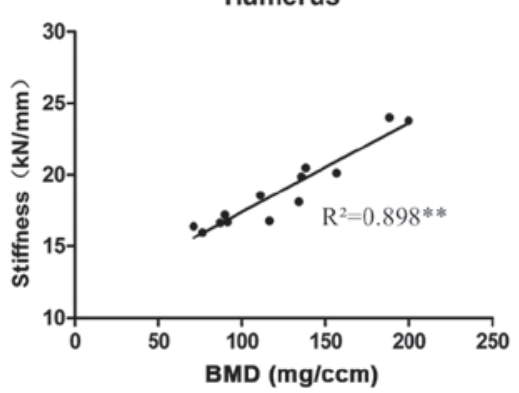

Humerus

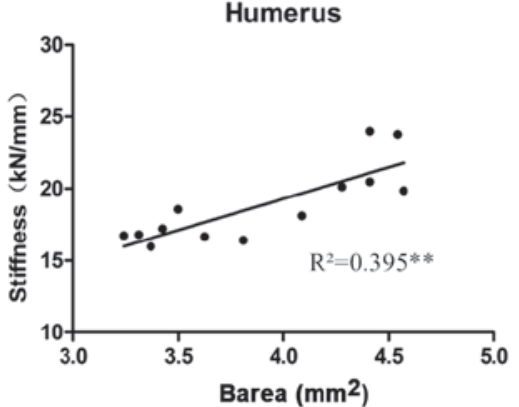

Vertebrae

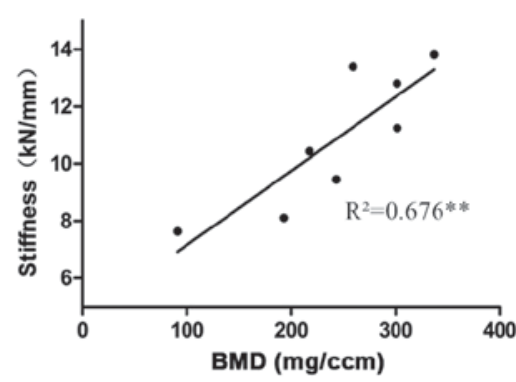

Vertebrae

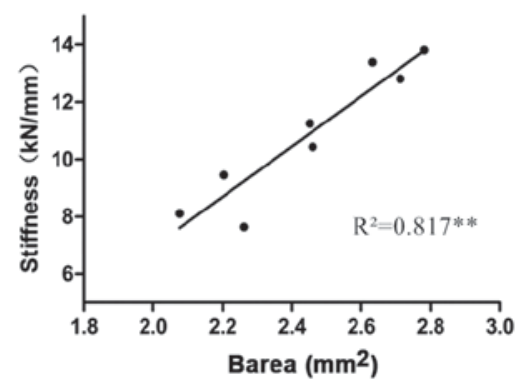

Figure 5. Correlation between microstructure parameters and stiffness. Scatter diagram and best-fit linear graphs for the correlation between microstructure parameters and stiffness. $\mathrm{P}<0.05 ;{ }^{* *} \mathrm{P}<0.01$. KD, ketogenic diet; $\mathrm{BMD}$, bone mineral density in trabecular bone.

bone loss under a KD for the first time, to the best of our knowledge, and evaluated the mechanical performance using a micro-FE model. These results establish a link between the microstructure and the function of bones. However, the dynamical changes in bone microstructure should also be evaluated at multiple time-points. For instance, the dynamic changes in bone microstructure and the effects of KD on cortical bone may be evaluated using in vivo micro-CT (41). In addition, the molecular mechanisms of bone loss caused by KD, which is expected to differ from the effects of a high-fat diet, was not determined in the present study; the effect of a KD on bone metabolism has been assessed by a previous study (40), but it should be further elucidated in the future.

In conclusion, the present study demonstrated that a KD led to bone loss and biomechanical reduction in appendicular bones, with a lesser impact on axial bones. Thickness was reduced in the cortical bone, and trabecular density was decreased in the cancellous bone in rats under $\mathrm{KD}$, also leading to decreased compressive stiffness and strength of appendicular bones. The present study demonstrated a significant correlation between the compressive properties and microstructural parameters of cancellous and cortical bones, respectively.

\section{Acknowledgements}

Not applicable.

\section{Funding}

This study was supported by National Science Foundation of China (grant no. 81472084), Guangdong Province Natural Science Foundation of China (grant no. 2015A030313276) and the Dean Foundation of Southern Medical University Nanfang Hospital (grant no. 2016Z021).

\section{Availability of data and materials}

All experimental data are available upon request from the corresponding author.

\section{Authors' contributions}

QZ, XW, JD and XX designed the experiments. QL and RL performed the animal experiments. $\mathrm{ZhH}$ and $\mathrm{ZuH}$ performed the experimental sampling. JD and XX wrote the manuscript. YL, JL, GK and ZY performed the data analysis, and QZ revised the manuscript.

\section{Ethical approval and informed consent}

The study was approved by the Nanfang Hospital Animal Experiments Ethics Committee (no. NFYY-2017-41). All animal experiments were performed according to the Guidelines for the Care of Laboratory Animals by the Ministry of Science and Technology of the P.R. China.

\section{Patient consent for publication}

Not applicable.

\section{Competing interests}

The authors declare that they have no competing interests.

\section{References}

1. Kose E, Guzel O, Demir K and Arslan N: Changes of thyroid hormonal status in patients receiving ketogenic diet due to intractable epilepsy. J Pediatr Endocrinol Metab 30: 411-416, 2017. 
2. McArtney R, Bailey A and Champion $\mathrm{H}$ : What is a ketogenic diet and how does it affect the use of medicines? Arch Dis Child Educ Pract Ed 102: 194-199, 2017.

3. Fukao T, Lopaschuk GD and Mitchell GA: Pathways and control of ketone body metabolism: On the fringe of lipid biochemistry. Prostaglandins Leukot Essent Fatty Acids 70: 243-251, 2004.

4. Krebs HA: The regulation of the release of ketone bodies by the liver. Adv Enzyme Regul 4: 339-354, 1966.

5. Van der Auwera I, Wera S, Van Leuven F and Henderson ST: A ketogenic diet reduces amyloid beta 40 and 42 in a mouse model of Alzheimer's disease. Nutr Metab (Lond) 2: 28, 2005.

6. Tai KK and Truong DD: Ketogenic diet prevents seizure and reduces myoclonic jerks in rats with cardiac arrest-induced cerebral hypoxia. Neurosci Lett 425: 34-38, 2007.

7. Tai KK, Nguyen N, Pham L and Truong DD: Ketogenic diet prevents cardiac arrest-induced cerebral ischemic neurodegeneration. J Neural Transm (Vienna) 115: 1011-1017, 2008.

8. Puchowicz MA, Zechel JL, Valerio J, Emancipator DS, Xu K, Pundik S, LaManna JC and Lust WD: Neuroprotection in diet-induced ketotic rat brain after focal ischemia. J Cereb Blood Flow Metab 28: 1907-1916, 2008.

9. Prins ML, Fujima LS and Hovda DA: Age-dependent reduction of cortical contusion volume by ketones after traumatic brain injury. J Neurosci Res 82: 413-420, 2005.

10. VanItallie TB, Nonas C, Di Rocco A, Boyar K, Hyams K and Heymsfield SB: Treatment of Parkinson disease with diet-induced hyperketonemia: A feasibility study. Neurology 64: 728-730, 2005.

11. Colica C, Merra G, Gasbarrini A, De Lorenzo A, Cioccoloni G, Gualtieri P, Perrone MA, Bernardini S, Bernardo V, Di Renzo L and Marchetti M: Efficacy and safety of very-low-calorie ketogenic diet: A double blind randomized crossover study. Eur Rev Med Pharmacol Sci 21: 2274-2289, 2017.

12. Mackay MT, Bicknell-Royle J, Nation J, Humphrey M and Harvey AS: The ketogenic diet in refractory childhood epilepsy. J Paediatr Child Health 41: 353-357, 2005.

13. Bergqvist AC, Schall JI, Stallings VA and Zemel BS: Progressive bone mineral content loss in children with intractable epilepsy treated with the ketogenic diet. AM J Clin Nutr 88: 1678-1684, 2008.

14. Wu X, Huang Z, Wang X, Fu Z, Liu J, Huang Z, Kong G, Xu X, Ding J and Zhu Q: Ketogenic diet compromises both cancellous and cortical bone mass in mice. Calcif Tissue Int 101: 412-421, 2017.

15. Bouxsein ML: Determinants of skeletal fragility. Best Pract Res Clin Rheumatol 19: 897-911, 2005.

16. Chen C, Zhang X, Guo J, Jin D, Letuchy EM, Burns TL, Levy SM, Hoffman EA and Saha PK: Quantitative imaging of peripheral trabecular bone micro-architecture using MDCT. Med Phys 45: 236-249, 2018.

17. Adachi JD, Loannidis G, Berger C, Joseph L, Papaioannou A, Pickard L, Papadimitropoulos EA, Hopman W, Poliquin S, Prior JC, et al: The influence of osteoporotic fractures on health-related quality of life in community-dwelling men and women across Canada. Osteoporos Int 12: 903-908, 2001.

18. Kazakia GJ, Nirody JA, Bernstein G, Sode M, Burghardt AJ and Majumdar S: Age- and gender-related differences in cortical geometry and microstructure: Improved sensitivity by regional analysis. Bone 52: 623-631, 2013.

19. Trombetti A, Stoermann C, Chevalley T, Van Rietbergen B, Herrmann FR, Martin PY and Rizzoli R: Alterations of bone microstructure and strength in end-stage renal failure. Osteoporos Int 24: 1721-1732, 2013.

20. Burghardt AJ, Kazakia GJ, Sode M, de Papp AE, Link TM and Majumdar S: A longitudinal HR-pQCT study of alendronate treatment in postmenopausal women with low bone density: Relations among density, cortical and trabecular microarchitecture, biomechanics, and bone turnover. J Bone Miner Res 25: 2558-2571, 2010.

21. Bertoli S, Trentani C, Ferraris C, De Giorgis V, Veggiotti P and Tagliabue A: Long-term effects of a ketogenic diet on body composition and bone mineralization in GLUT-1 deficiency syndrome: A case series. Nutrition 30: 726-728, 2014.

22. Simm PJ, Bicknell-Royle J, Lawrie J, Nation J, Draffin K, Stewart KG, Cameron FJ, Scheffer IE and Mackay MT: The effect of the ketogenic diet on the developing skeleton. Epilepsy Res 136: 62-66, 2017.

23. Caminhotto RO, Komino ACM, de Fatima Silva F, Andreotti S, Sertié RAL, Boltes Reis G and Lima FB: Oral $\beta$-hydroxybutyrate increases ketonemia, decreases visceral adipocyte volume and improves serum lipid profile in Wistar rats. Nutr Metab (Lond) 14: 31, 2017.
24. Newell C, Bomhof MR, Reimer RA, Hittel DS, Rho JM and Shearer J: Ketogenic diet modifies the gut microbiota in a murine model of autism spectrum disorder. Mol Autism 7: 37, 2016.

25. Urbain P and Bertz H: Monitoring for compliance with a ketogenic diet: What is the best time of day to test for urinary ketosis? Nutr Metab (Lond) 13: 77, 2016.

26. Veldhorst MA, Westerterp-Plantenga MS and Westerterp KR: Gluconeogenesis and energy expenditure after a high-protein, carbohydrate-free diet. Am J Clin Nutr 90: 519-526, 2009.

27. Cahill GJ Jr: Fuel metabolism in starvation. Annu Rev Nutr 26: $1-22,2006$.

28. Johnstone AM, Horgan GW, Murison SD, Bremner DM and Lobley GE: Effects of a high-protein ketogenic diet on hunger, appetite, and weight loss in obese men feeding ad libitum. Am J Clin Nutr 87: 44-55, 2008.

29. Meyer HE, Sogaard AJ, Falch JA, Jorgensen L and Emaus N: Weight change over three decades and the risk of osteoporosis in men: The norwegian epidemiological osteoporosis studies (NOREPOS). Am J Epidemiol 168: 454-460, 2008.

30. Sampath A, Kossoff EH, Furth SL, Pyzik PL and Vining EP: Kidney stones and the ketogenic diet: Risk factors and prevention. J Child Neurol 22: 375-378, 2017

31. Tamaki J, Iki M, Sato Y,Kajita E, Nishino H, Akiba T, Matsumoto T and Kagamimori S; JPOS Study Group: Total 25-hydroxyvitamin D levels predict fracture risk: Results from the 15-year follow-up of the Japanese Population-based Osteoporosis (JPOS) Cohort study. Osteoporos Int 28: 1903-1913, 2017.

32. Schönenberg D, Guggenberger R, Frey D, Pape HC, Simmen HP and Osterhoff G: CT-based evaluation of volumetric bone density in fragility fractures of the pelvis-a matched case-control analysis. Osteoporos Int 29: 459-465, 2018.

33. Macneil JA and Boyd SK: Bone strength at the distal radius can be estimated from high-resolution peripheral quantitative computed tomography and the finite element method. Bone 42: 1203-1213, 2008 .

34. Pistoia W, van Rietbergen B, Lochmüller EM, Lill CA, Eckstein F and Rüegsegger P: Estimation of distal radius failure load with micro-finite element analysis models based on three-dimensional peripheral quantitative computed tomography images. Bone 30: 842-848, 2002.

35. Nobakhti S and Shefelbine SJ: On the relation of bone mineral density and the elastic modulus in healthy and pathologic bone. Curr Osteoporos Rep 16: 404-410, 2018.

36. Hildebrand T, Laib A, Müller R, Dequeker J and Rüegsegger P: Direct three-dimensional morphometric analysis of human cancellous bone: Microstructural data from spine, femur, iliac crest, and calcaneus. J Bone Miner Res 14: 1167-1174, 1999.

37. Buckley JM, Loo K and Motherway J: Comparison of quantitative computed tomography-based measures in predicting vertebral compressive strength. Bone 40: 767-774, 2007.

38. Newman JC and Verdin E: Ketone bodies as signaling metabolites. Trends Endocrinol Metab 25: 42-52, 2014.

39. Carter JD, Vasey FB and Valeriano J: The effect of a low-carbohydrate diet on bone turnover. Osteoporos Int 17: 1398-1403, 2006.

40. Saito A, Yoshimura K, Miyamoto Y, Kaneko K, Chikazu D, Yamamoto $\mathrm{M}$ and Kamijo R: Enhanced and suppressed mineralization by acetoacetate and $\beta$-hydroxybutyrate in osteoblast cultures. Biochem Biophys Res Commun 473: 537-544, 2016.

41. Waarsing JH, Day JS, van der Linden JC, Ederveen AG, Spanjers C, De Clerck N, Sasov A, Verhaar JA and Weinans H: Detecting and tracking local changes in the tibiae of individual rats: A novel method to analyse longitudinal in vivo micro-CT data. Bone 34 : $163-169,2004$.

This work is licensed under a Creative Commons Attribution-NonCommercial-NoDerivatives 4.0 International (CC BY-NC-ND 4.0) License. 